Check for updates

Cite this: RSC Adv., 2018, 8, 37069

Received 17th September 2018 Accepted 29th October 2018

DOI: $10.1039 / \mathrm{c} 8 \mathrm{ra0} 7725 \mathrm{~h}$

rsc.li/rsc-advances

\section{Arbuscular mycorrhizal inoculation increases molybdenum accumulation but decreases molybdenum toxicity in maize plants grown in polluted soil $\dagger$}

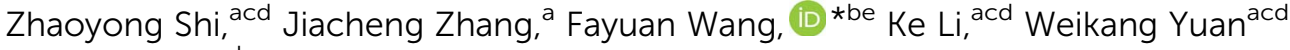 \\ and Jianbo Liu ${ }^{\mathrm{b}}$
}

Molybdenum (Mo) is an important micronutrient required by both plants and microorganisms, but may become toxic when presents in excess concentration. However, Mo toxicity in soil-plant systems as influenced by arbuscular mycorrhizal (AM) fungi (AMF) still remains unknown. Here, a pot culture experiment was conducted to study the effects of inoculation with Claroideoglomus etunicatum BEG 168 on the growth and Mo content of maize plants growing in soil supplemented with different levels $(0$, 1000, 2000, and $4000 \mathrm{mg} \mathrm{kg}^{-1}$ ) of Mo. Results show that the added Mo had no significant effects on AM colonization rate, which ranged from $77 \%$ to $92 \%$. Mo addition decreased plant dry weights and leaf pigment contents, as well as nutrient uptake of $\mathrm{P}, \mathrm{N}, \mathrm{Fe}, \mathrm{Mg}$ and $\mathrm{Cu}$ in shoots and roots, and in most cases, the highest level $\left(4000 \mathrm{mg} \mathrm{kg}^{-1}\right.$ ) showed the most inhibitory effects. Overall, AM inoculation enhanced plant growth, mineral nutrient uptake, leaf pigment contents and photosynthetic rate under all Mo addition levels. Mo concentrations in plants without Mo addition ranged from 13.1 to $40.1 \mathrm{mg} \mathrm{kg}^{-1}$ in roots, and from 42.8 to $58.4 \mathrm{mg} \mathrm{kg}^{-1}$ in shoots. Addition of Mo increased Mo concentrations in both shoots and roots of all the plants, but showed no significant dose-dependent effects. In non-inoculated plants receiving Mo addition, Mo concentrations were not lower than $400 \mathrm{mg} \mathrm{kg}^{-1}$ in shoots and higher than $1300 \mathrm{mg} \mathrm{kg}^{-1}$ in roots respectively. AM inoculation further enhanced Mo concentrations in shoots and roots, but decreased shoot/root Mo ratio at 2000 and $4000 \mathrm{mg} \mathrm{kg}^{-1}$ Mo addition levels. In AM inoculation treatments, soil $\mathrm{pH}$ exhibited a decreasing trend with increasing Mo addition level. In conclusion, excess Mo caused toxicity in maize plants, while AM fungus C. etunicatum BEG 168 was tolerant to the added Mo, and could alleviate the Mo-induced phytotoxicity by improving plants' mineral nutrition, leaf pigment contents and photosynthetic properties, and by mediating Mo partitioning in plants and soil $\mathrm{pH}$. Our present results suggest a specific protection mechanism exists in AM plants against excess Mo, and their promising potential in ecological restoration and phytoremediation of Mopolluted sites.
${ }^{a}$ College of Agriculture, Henan University of Science and Technology, Luoyang, Henan Province, 471023, P. R. China

${ }^{b}$ College of Environment and Safety Engineering, Qingdao University of Science and Technology, Qingdao, Shandong Province, 266042, P. R. China. E-mail: wangfayuan@qust.edu.cn

'Luoyang Key Laboratory of Plant Nutrition and Environmental Ecology, Luoyang, Henan Province, 471023, P. R. China

${ }^{d}$ Luoyang Key Laboratory of Symbiotic Microorganism and Green Development, Luoyang, Henan Province, 471023, P. R. China

${ }^{e}$ Key Laboratory of Soil Resources and Environment in Qianbei of Guizhou Province, Zunyi Normal University, Zunyi, Guizhou Province, 563002, P. R. China

$\dagger$ Electronic supplementary information (ESI) available. See DOI: $10.1039 / \mathrm{c} 8 \mathrm{ra} 07725 \mathrm{~h}$

\section{Introduction}

Molybdenum (Mo) is a trace metal occurring in soil and is among the essential micronutrients for most organisms including plants and animals. ${ }^{1}$ Mo is a component element of several important enzymes within plant tissues, such as nitrate reductase, nitrogenase, sulfite oxidase, and xanthine dehydrogenase. It benefits plant growth and development at optimum levels, but induces phytotoxicity at excess levels. The Mo accumulated in plants, in particular in crops, may enter the food chain, posing a potential health risk to human beings and animals. A previous study showed that ruminants (cattle) feeding on herbage with high Mo concentrations $\left(10-20 \mu \mathrm{g} \mathrm{g}^{-1}\right)$ suffered from Mo poisoning, which can often be fatal. ${ }^{2}$ 
Therefore, the accumulation of Mo in crop plants should be addressed.

Normal Mo concentrations in the tissues of common crops usually range from 0.8 to $5 \mathrm{mg} \mathrm{kg}{ }^{-1} \cdot{ }^{3}$ However, the values vary widely with plant species, ranging from $0.01 \mathrm{mg} \mathrm{kg} \mathrm{kg}^{-1}$ in common crops to several hundred $\mathrm{mg} \mathrm{kg}^{-1}$ in legumes. ${ }^{4}$ Although Mo is less phytotoxic than other trace metals such as $\mathrm{Cu}$ and $\mathrm{Zn}$, excessive Mo may cause chlorosis and yellowing in plants via interfering with Fe metabolism. ${ }^{5}$ In fields, Mo content in plants is closely related to Mo levels in the soil, ${ }^{5}$ which can be elevated by human activities. An investigation has shown that industrial utilization led to Mo accumulation in soil and groundwater, posing potential health risk. ${ }^{6}$ Mining and processing of Mo ore also releases a large amount of Mo into the surrounding environments. ${ }^{5}$ Mo concentrations in the miningaffected soils reached up to $1071.52 \mathrm{mg} \mathrm{kg}^{-1}$ and $2903.91 \mathrm{mg}$ $\mathrm{kg}^{-1,8}$ respectively. In an agricultural field surrounding a Mo mining site, the Mo concentrations in the rice grains ranged from 0.58 to $12.04 \mathrm{mg} \mathrm{kg}^{-1}$, indicating a possible pollution and a potential health risk for rice-consumers. ${ }^{9}$ Unfortunately, to date, little has been known on Mo effects and toxicity in soilplant system.

The roles of microorganisms in cleaner production and sustainable development have attracted increasing attention. ${ }^{\mathbf{1 0}}$ Arbuscular mycorrhizal (AM) fungi (AMF) represent a group of ubiquitous symbiotic microorganisms belonging to the Glomeromycota, and form mutualistic associations with a majority of higher plants in terrestrial ecosystems, including heavy metalpolluted soils. ${ }^{\mathbf{1 1} 12}$ Apart from their excellent ability to improve plant mineral nutrients (notably P), AMF can alleviate the phytotoxicity of various trace metals/metalloids such as $\mathrm{Cu}, \mathrm{Zn}$, $\mathrm{Pb}, \mathrm{Cd}, \mathrm{Cr}, \mathrm{Ni}$, As, helping plants to grow better in metalpolluted and mining-impacted soils. ${ }^{\mathbf{1 3 , 1 4}}$ However, AMF effects on plant tolerance to Mo toxicity still remain unknown.

The mobility and bioavailability of Mo in soil are largely dependent on soil $\mathrm{pH}$, and influenced by soil P. ${ }^{5}$ Under heavy metal pollution, AMF often cause soil $\mathrm{pH}$ to rise and improve plant $\mathrm{P}$ nutrition. ${ }^{\mathbf{1 5 , 1 6}} \mathrm{AMF}$ have been shown to enhance Mo acquisition by plants growing on non-polluted soil via diverse mechanisms. ${ }^{17,18}$ Putatively, AMF probably affect Mo toxicity and accumulation in plants under Mo-polluted condition. Here, a soil culture experiment was conducted using maize inoculated with or without $C$. etunicatum grown in soil with different Mo addition levels. Our aims are to test: (1) the effects of Mo on maize growth, nutritional status, Mo accumulation, and physiological responses, especially when the Mo added reaches a stress level; (2) if AM colonization can mitigate Mo toxicity; and (3) the possible protection mechanisms against Mo toxicity used by AMF.

\section{Materials and methods}

\section{AMF inoculum and soil}

The AM fungus Claroideoglomus etunicatum (formerly Glomus etunicatum) BEG 168, from China Agricultural University, was propagated on maize (Zea mays) plants grown in pots with sterilized sand for 12 weeks. ${ }^{19}$ The AM inoculum consisted of a mixture of spores, mycelia, sand and root fragments, with about 1000 spores per $100 \mathrm{~g}$.

A loamy soil taken from a cropland was used in the present experiment. To eliminate the impact of native AMF, the soil was sterilized at $121{ }^{\circ} \mathrm{C}$ for $60 \mathrm{~min},{ }^{19}$ and then air-dried for pot culture. Soil properties are as follows: $\mathrm{pH}(1: 2.5$, soil/water $)$ $7.32,7.6 \%$ organic matter, $13 \mathrm{~g} \mathrm{~kg}^{-1}$ total $\mathrm{N}, 337.3 \mathrm{mg} \mathrm{kg} \mathrm{kg}^{-1}$ total $\mathrm{P}, 2.7 \mathrm{~g} \mathrm{~kg}^{-1}$ total $\mathrm{K}$, and $8.4 \mathrm{mg} \mathrm{kg}^{-1}$ total Mo.

\section{Experimental procedure}

The levels of Mo were added according to the results from our surveys of soil Mo pollution of mining-affected farmland. The Mo concentrations sometimes reach as high as one to several thousand $\mathrm{mg} \mathrm{kg}^{-1}$. In the present study, four levels of Mo (0, 1000, 2000, and $4000 \mathrm{mg} \mathrm{kg}^{-1}$ ) were set, representing no, slight, moderate, and severe pollution, respectively. The solution of $\left(\mathrm{NH}_{4}\right)_{2} \mathrm{MoO}_{4}$ (analytical grade) was mixed thoroughly with the soil to simulate Mo pollution. In order to eliminate the difference of $\mathrm{N}$ caused by different levels of $\left(\mathrm{NH}_{4}\right)_{2} \mathrm{MoO}_{4}$, an appropriate amount (1050, 787.5, $525 \mathrm{mg}$ per pot) of $\mathrm{NH}_{4} \mathrm{NO}_{3}$ was mixed to the soil of the first three addition levels respectively. Half of the treatments were inoculated with $C$. etunicatum BEG 168 , and the other half remained non-inoculated. Plastic pots with $17 \mathrm{~cm}$ height $\times 13 \mathrm{~cm}$ diameter were used. For AM inoculation treatments, $100 \mathrm{~g}$ air-dried AM inoculum was mixed uniformly into each pot filled with $900 \mathrm{~g}$ air-dried soil, while $100 \mathrm{~g}$ sterilized AM inoculum per pot was used to create noninoculation treatments. To maintain similar microbial communities, $10 \mathrm{~mL}$ of AM inoculum filtrate was irrigated into each pot. ${ }^{20}$ Thus, this is a bi-factorial experiment with a $4 \times 2$ design. Each treatment had 4 replicates.

Seeds of maize (Weike702) were provided by Henan Jinyuan Seeds Co. Ltd. Eight surface-sterilized seeds with uniform size were sown in each pot. After one week, the seedlings were thinned to five per pot. The seedlings were placed in an artificially controlled plant growth chamber, with a day/night (12/12 h) of $28-30 / 23-26{ }^{\circ} \mathrm{C}$ (light intensity 5000 lux), and a relative humidity of $50-80 \%$. Seedlings were irrigated with tap water when needed.

\section{Plant and soil analysis}

After 4 weeks of plant growth, shoots and roots were harvested separately. Subsamples of fresh roots and leaves were taken to evaluate root colonization rate and leaf pigment content respectively. The remaining plant materials were oven-dried at $70{ }^{\circ} \mathrm{C}$ for $48 \mathrm{~h}$ and then ground for further element analysis. The soil in each pot was totally mixed and sampled for analysis of soil pH.

Root colonization rate was assessed using an ink staining method. ${ }^{21}$ The dried plant materials, as well as standard plant material (GBW07603, GSV-2), were wet-digested in a mixture of concentrated sulfuric acid and hydrogen peroxide for elemental analysis. Concentrations of $\mathrm{Mo}, \mathrm{P}, \mathrm{Fe}, \mathrm{Mg}$, and $\mathrm{Cu}$ were determined using ICP-OES (Optima 7300 DV, Perkin-Elmer, USA). Plant $\mathrm{N}$ concentration was determined using an Elementar Vario-Macro carbon-nitrogen analyzer (Elementar 
Analysensysteme, GmbH, Germany). Soil pH was measured in a $1: 2.5(\mathrm{w} / \mathrm{v})$ soil/water suspension using an electronic $\mathrm{pH}$ meter (Rex PHS-25, INESA Scientific Instrument Co., Ltd, China).

The contents of leaf photosynthetic pigments including chlorophyll (chl) and carotenoid were assayed by extracting fresh leaves in 95\% ethanol solution, and then measuring the absorbance at 470,649, and $665 \mathrm{~nm}$. The contents of chl $a$, chl $b$ and carotenoid were calculated. ${ }^{22}$

Net photosynthesis and transpiration rate were determined using a portable photosynthesis system (Li-6400XT, Li-Cor, Lincoln, USA). Three matured leaves per pot were selected at mid-morning before plant harvest (September 10, 2017) to measure the net photosynthetic rate $\left(P_{\mathrm{n}}\right)$ and transpiration rate $(E)$.

\section{Statistical analysis}

Data was analyzed using SPSS 22.0 software. A one-way ANOVA $(P<0.05)$ followed by Duncan's test was used to compare statistical significance among the treatments. Two-way ANOVA analysis was performed to test the significance of interactions between the factors Mo addition levels and AM inoculation.

\section{Results and discussion}

\section{Soil pH and mycorrhizal colonization}

Compared with the initial soil pH (7.32), soil pH after plant growth was increased in all the treatments (Fig. 1a). Compared to the zero addition level, Mo addition did not influence soil $\mathrm{pH}$ in non-AM treatments, but decreased soil $\mathrm{pH}$ at 2000 and $4000 \mathrm{mg} \mathrm{kg}^{-1}$ in AM treatments. Compared with the non-AM treatments, AM inoculation did not change soil $\mathrm{pH}$ significantly at all the Mo addition levels. It has been found that the bioavailability and the phytotoxicity of Mo highly depends on soil $\mathrm{pH}$, and generally positively correlates with soil $\mathrm{pH}{ }^{5}$ Soil amended with Mo all had a similar $\mathrm{pH}$, which may partly

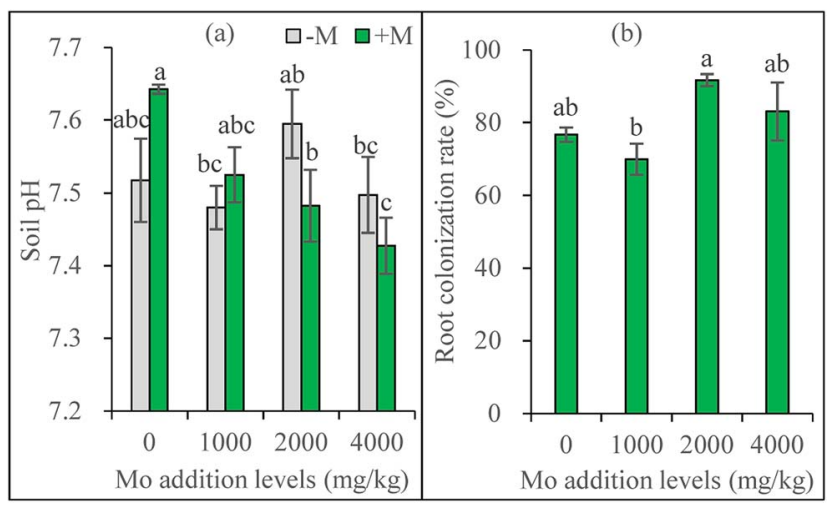

Fig. 1 Soil $\mathrm{pH}(\mathrm{a})$ and root colonization rate (b) of maize plants after harvest. $-M$ and $+M$ represent non $A M$-inoculation and inoculation with C. etunicatum BEG 168, respectively. Different letters on the bars indicate significant differences among all means in different treatments using a one-way ANOVA followed by the Duncan's multiple range test $(P<0.05)$. explain why the plants receiving Mo had a narrow range of Mo concentration.

However, soil pH in AM inoculated treatments exhibited a decreasing trend with increasing Mo addition level, suggesting AMF may mitigate Mo availability through regulating soil $\mathrm{pH}$. In our previous studies, AMF were found to alleviate the availability and toxicity of heavy metals via inducing a higher soil $\mathrm{pH}^{\mathbf{1 6 , 2 3}}$ These conflicting results imply AMF may actively select different adaptation strategies against various stresses. Combining the fact of higher Mo concentrations in their tissues, AM plants may employ a specific protection mechanism against Mo toxicity.

The control plants receiving no AM inoculation were not colonized. The inoculated plants were all highly colonized, with the root colonization rates ranging from $77 \%$ to $92 \%$ (Fig. 1b). Compared to the zero addition level, Mo addition levels did not significantly influence mycorrhizal colonization. However, the plants receiving $2000 \mathrm{mg} \mathrm{kg}^{-1}$ Mo addition had significantly higher colonization rate than those receiving $1000 \mathrm{mg} \mathrm{kg}^{-1}$.

AMF occur in sites polluted with various metals and can develop tolerance to excess levels of many trace elements. ${ }^{\mathbf{1 4 , 2 4}}$ The present results showed for the first time that the added Mo had no toxic and even stimulatory effects on AM colonization, suggesting a low fungitoxicity of Mo and a good Mo tolerance in the studied AM species. Mo is an essential micronutrient for both plants and microorganisms such as rhizobia and mycorrhizal fungi. ${ }^{25}$ Previous study found adding an appropriate amount of Mo to the rhizobial inoculum could increase the survival of the rhizobial cells. ${ }^{26}$ Similarly, the low toxicity and even stimulatory effects of Mo on AM colonization are expected. However, the threshold values for Mo toxicity in AMF and other influencing factors need to be explored in future studies.

\section{Plant growth, leaf photosynthesis and transpiration, and Mo concentrations}

As shown by the one-way ANOVA results, compared to the zero addition treatments, shoot DWs of non-inoculated plants decreased at $4000 \mathrm{mg} \mathrm{kg}{ }^{-1}$ Mo addition level, and their root DWs decreased at 2000 and $4000 \mathrm{mg} \mathrm{kg}^{-1}$ (Fig. 2a and b). Plant height was decreased only at $4000 \mathrm{mg} \mathrm{kg}^{-1}$ Mo addition level (Fig. S1†). In most cases, Mo addition decreased shoot and root DWs of AM-inoculated plants. Excess Mo causes toxic effects in plants, such as alteration of morphology, cell structures and physiological responses. ${ }^{27,28}$ However, the toxicity threshold values of Mo greatly varied with soil properties and plant species, with a wide range of added Mo concentrations generating $50 \%$ inhibition of plant growth $\left(\mathrm{ED}_{50}\right)$ among the surveyed 10 soils, ranging from less than $1 \mathrm{mg} \mathrm{kg}^{-1}$ to higher than several thousand $\mathrm{mg} \mathrm{kg}^{-1}$, and ryegrass showed higher resistance to Mo toxicity than other three crops (oilseed rape, red clover, and tomato). ${ }^{29}$ In the present study, the added Mo caused plant growth reduction in most cases, suggesting a phytotoxic effect on maize grown in the studied soil. Meanwhile, $1000 \mathrm{mg} \mathrm{kg}^{-1}$ Mo did not significantly inhibit the growth of non-inoculated plants, indicating a strong Mo 


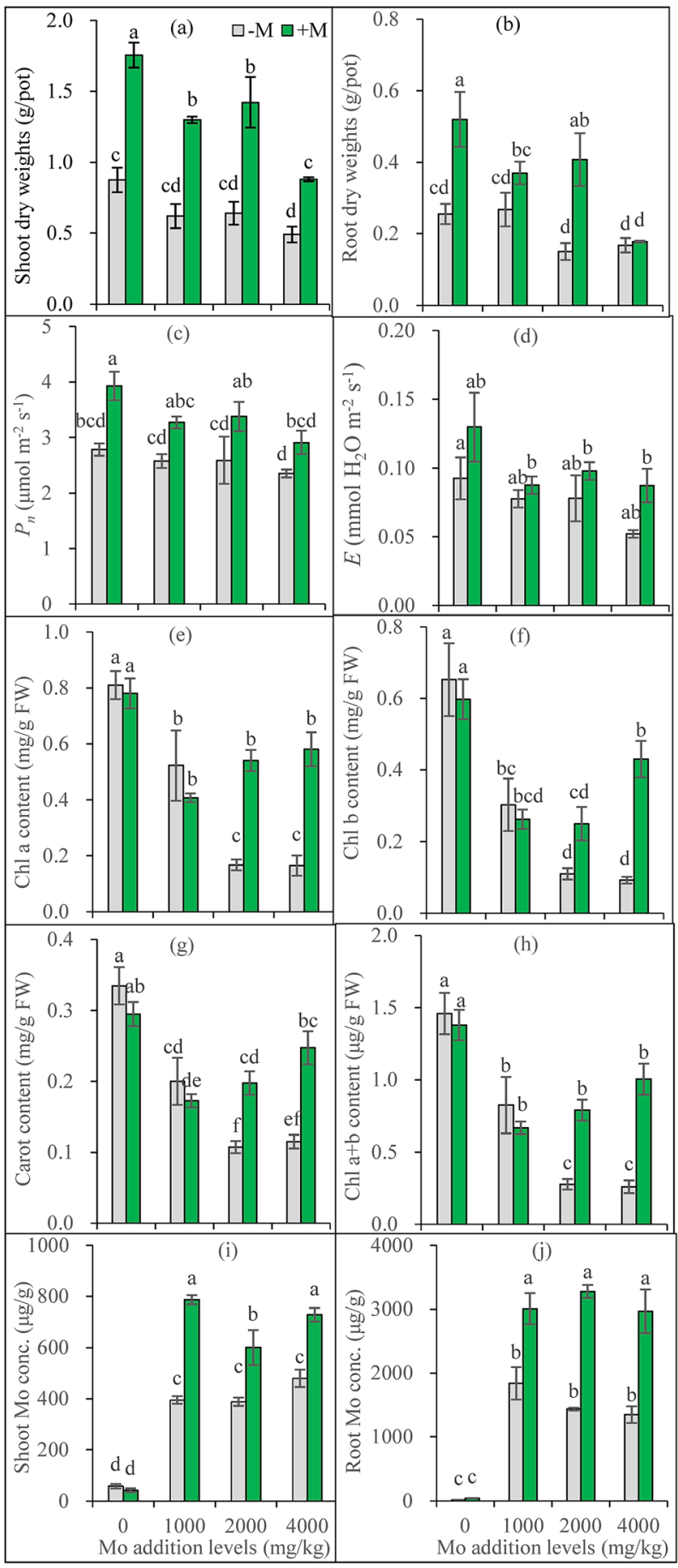

Fig. 2 Dry weights of maize shoots (a) and roots (b), net photosynthesis $\left(P_{n}\right)(\mathrm{c})$ and transpiration rate $(E)(\mathrm{d})$, contents of chl a (e), chl $b(\mathrm{f})$, $\mathrm{chl} a+b(\mathrm{~h})$ and carotenoid (g) in maize leaves, and Mo concentrations in maize shoots (i) and roots (j). $-M$ and $+M$ represent non $A M$-inoculation and inoculation with C. etunicatum BEG 168, respectively. Different letters on the bars indicate significant differences among all means in different treatments using a one-way ANOVA followed by the Duncan's multiple range test $(P<0.05)$.

tolerance in maize. This supports the previous finding that monocotyledonous plants like Gramineae are generally more tolerant to excess Mo than dicotyledonous species. ${ }^{30}$
The growth of AM inoculated plants was also inhibited by Mo addition, indicating a Mo toxicity occurred in AM plants (Fig. 2a and b). However, AM colonization was not inhibited (Fig. 1b). Compared with the non-inoculated plants, AM-inoculated plants generally had higher shoot and root DWs under all Mo addition levels (except for root DWs at $4000 \mathrm{mg} \mathrm{kg}^{-1}$ ) (Fig. 2a, $\mathrm{b}$ and $\mathrm{S} 1 \dagger$ ), confirming AM plants have stronger tolerance to Mo stress. Numerous studies have shown AMF help their host plants to resist various environmental stresses such as trace metal pollution and salinity. ${ }^{14,31}$ Our present results confirm the AM fungus C. etunicatum is tolerant to Mo stress and can help plants to resist Mo-induced toxicity.

Net photosynthesis $\left(P_{\mathrm{n}}\right)$ and transpiration rate $(E)$ both showed decreasing trends with the increasing Mo addition levels, although no significant inhibitory effects were observed based on the one-way ANOVA results (Fig. 2c and d). Apparently, the lower pigments in leaves caused by excess Mo may lead to a lower photosynthetic rate, consequently decreasing photosynthate production and plant biomass.

Overall, AM plants generally had higher photosynthetic rate and transpiration rate in leaves (Fig. $2 \mathrm{c}$ and d), indicating AMF not only increased carbon (C) fixation during photosynthesis, but also improved stomatal gas exchange capacity and water uptake. Improved pigments in leaves and plant nutrient and water uptake by AMF may partly account for why AM plants perform photosynthesis and transpiration better. A previous study has shown that, under Cd stress, AMF not only increased chlorophyll content of Lolium perenne, but also promoted PSII photochemical activity, and enhanced plants' adaptation to $\mathrm{Cd}$ contamination via optimizing light energy allocation and utilization. ${ }^{32}$ Our present study found the similar benefits from AM inoculation for maize to overcome stress caused by excess Mo.

Mo addition significantly decreased the contents of $\operatorname{chl} a, \mathrm{chl}$ $b$, and carotenoid in maize leaves, but no significant difference was observed between 2000 and $4000 \mathrm{mg} \mathrm{kg}^{-1}$ Mo addition levels in non-inoculated plants (Fig. 2e-h). Chlorophyll is essential for plants to perform photosynthesis, which enables plants to capture light energy. Previous studies have shown that heavy metal stress decreases the synthesis of photosynthetic pigments, ${ }^{20,33}$ thus impairing photosynthesis and leading to a decreased plant biomass accumulation. Excess Mo decreased $\mathrm{Mg}$ and Fe uptake by plants, which may partly explain the lower contents of leaf pigments.

Many studies have found AMF increase the chlorophyll content in leaves of different plants under various stresses..$^{20,32,34}$ In the present study, AM inoculation improved the contents of leaf pigments in plants receiving 2000 and $4000 \mathrm{mg} \mathrm{kg}^{-1} \mathrm{Mo}$, but did not show significant impacts at 0 and $1000 \mathrm{mg} \mathrm{kg}^{-1}$. The increase of leaf pigments might be partly attributed to the improved nutrients such as $\mathrm{Fe}, \mathrm{Mg}, \mathrm{Cu}$, and $\mathrm{P}$ by $\mathrm{AM}$ colonization. However, AM inoculation displayed no significant effects at $1000 \mathrm{mg} \mathrm{kg}^{-1}$ Mo addition level, indicating Mo toxicity to AMF is complex, and the dosage is not the only determinant.

As show in Fig. 2i and j, Mo concentrations in plants without Mo addition ranged from 13.1 to $40.1 \mathrm{mg} \mathrm{kg}^{-1}$ in roots, and from 42.8 to $58.4 \mathrm{mg} \mathrm{kg}^{-1}$ in shoots, much higher than the ranges ( 0.80 to $5.0 \mathrm{mg} \mathrm{kg}^{-1}$ ) in common crop plants. ${ }^{3}$ This can 
be attributed to the much higher Mo background values $(8.4 \mathrm{mg}$ $\mathrm{kg}^{-1}$ ) in the soil used. However, Mo concentrations vary widely with plant species, reaching $>15 \mathrm{mg} \mathrm{kg}^{-1}$ in some plants. ${ }^{5}$ Generally, the presence of Mo ranging from 100 to $200 \mathrm{mg} \mathrm{kg}^{-1}$ in plants does not cause any toxicity appearance on the foliage. ${ }^{5}$ Here, no toxic symptoms were observed on the plants grown in soil without added Mo.

Plants can actively take up exogenous molybdate by roots and transport to the shoot. ${ }^{27,35}$ Mo concentrations reached $500 \mathrm{mg} \mathrm{kg}^{-1}$ and $>1000 \mathrm{mg} \mathrm{kg}^{-1}$ in maize shoots and roots respectively when the soil was added with $270 \mathrm{mg} \mathrm{kg}^{-1} \mathrm{Mo.}^{27}$ Similar results were obtained in the present study: Mo addition significantly increased Mo concentrations in both shoots and roots of all plants (Fig. $2 \mathrm{i}$ and j). In non-inoculated plants, Mo concentrations were not lower than $400 \mathrm{mg} \mathrm{kg}^{-1}$ in shoots and higher than $1300 \mathrm{mg} \mathrm{kg}^{-1}$ in roots respectively. A previous study has found that shoot Mo concentrations inducing $10 \%$ growth inhibition $\left(\mathrm{EC}_{10}\right)$ range from 52 to $3764 \mathrm{mg} \mathrm{kg}{ }^{-1}$ for four different crops grown in ten soils tested. ${ }^{29}$ In the present study, the shoot Mo (400 $\mathrm{mg} \mathrm{kg}^{-1}$ or higher) produced a shoot growth reduction from $27 \%$ to $44 \%$, confirming the Mo concentration is excess and toxic to plants.

Generally, Mo concentrations in maize plants increased gradually with the increasing levels of Mo added to the growth substrate. ${ }^{27,28}$ Differently, our present study showed plant Mo concentrations did not increase with the increasing Mo addition levels, suggesting the existence of an active defense mechanism that prevents excess Mo into the root. Similarly, Mo accumulated in the Ophioglossum plant against a concentration gradient and reached a final concentration of the element which significantly exceeded the soil soluble Mo concentration. ${ }^{36}$ Our present results also confirm that plants accumulated more Mo in roots than in shoots, ${ }^{28}$ leading to less Mo translocated into shoots, which represents another possible metal tolerance mechanism employed by excluder plants surviving in heavy metal-stressed environments. ${ }^{37}$

The most important finding of the present study was that AM inoculation always increased Mo concentrations in shoots and roots of plants grown in soil amended with Mo. This is really beyond our expectations, because higher plant Mo content exceeding plants' requirement generally means stronger toxicity, which is apparently contrary to the fact that AM plants grew better (Fig. 2i and j). One most common mechanism underlying AM plants' resistance to heavy metal toxicity is the biomass dilution effect of the toxic metals owing to plant growth-promoting effects induced by AMF. ${ }^{16}$ Apparently, the dilution mechanism is unlikely to be involved in our present study. Under heavy metal stress, AMF often increase the partitioning of toxic metals into roots and depress their translocation to shoots via immobilization of AM structures and exudate such as glomalin-related soil protein. ${ }^{14}$ At 2000 and $4000 \mathrm{mg} \mathrm{kg}^{-1}$ Mo addition levels, AM plants had a lower shoot/ root ratio of Mo concentrations than non-inoculated plants (Fig. S2 $\dagger$ ), confirming this is a protection mechanism against excess Mo adopted by AM plants. There may be other strategies in AM plants to deal with the excess Mo both in them and their growing environments. For example, excess Mo causes oxidative stress in plants, ${ }^{28}$ but AMF may enhance plant antioxidant capacity via modifying antioxidant enzyme activity. ${ }^{\mathbf{1 4}}$

\section{Plant nutrient uptake}

Based on the one-way ANOVA results, Mo addition and AM inoculation had significant influences on shoot $\mathrm{P}$ uptake but did not change root uptake (Fig. 3a and b). Synergistic interaction often occurs between soil $\mathrm{P}$ and Mo uptake by plants. ${ }^{5}$ The elevated soil $\mathrm{P}$ can compete with Mo for adsorption sites, ${ }^{38}$ and thus molybdates could be released from the anionexchange complex by $\mathrm{H}_{2} \mathrm{PO}_{4}{ }^{-}$replacement, leading to increased soil solution Mo available for plant uptake. In a hydroponic trial, added $\mathrm{P}$ increased Mo uptake in Brassica napus shoots, and improved Mo translocation from roots to shoots. ${ }^{39}$ This can also partly explain why AM plants had higher Mo accumulation than non-AM plants: the AMF-increased soil available $\mathrm{P}$ may enhance more available Mo to release into soil solution absorbed by plants.

However, Mo addition decreased P uptake in shoots, and in AM plant shoots, $\mathrm{P}$ uptake decreased with the increasing Mo addition levels (Fig. 3a and b). These facts suggest a possible competition occurs between the transport of Mo and P from roots to shoots, particularly when one of them is excess. Heuwinkel et $a .^{40}$ found that $\mathrm{P}$ deficiency increased Mo uptake by tomato plants, and inferred molybdate might be taken up by a phosphate transporter. This may partly explain why excess Mo decreased shoot $\mathrm{P}$ accumulation. AMF have been shown to actively regulate expressions of phosphate transporter genes in plants. ${ }^{41}$ Thus, it can be inferred that under Mo stress AM plants actively mediate Mo transport via regulating Mo transporters to maintain a constant Mo concentration.

Mo is a cofactor in nitrate reductase that catalyzes the first step of the assimilatory nitrate reduction, ${ }^{25}$ thus playing important role in plant $\mathrm{N}$ metabolism and nutrition. Mo deficiency often leads to a poor $\mathrm{N}$ nutrition, and/or an imbalanced $\mathrm{N}$ metabolism. ${ }^{42}$ Our present results show that excess Mo decreased $\mathrm{N}$ uptake by roots and transport to shoots (Fig. 3c and d). However, these negative responses were partially offset by AM inoculation (Fig. 3c and d). Ammonium transporter genes have been identified from AM fungal extraradical hyphae. ${ }^{\mathbf{4 3 , 4 4}}$ The extraradical hyphae can capture $\mathrm{N}$ sources from soil and translocate them to the plants through the intraradical mycelium.

In most cases, Mo addition significantly decreased $\mathrm{Fe}, \mathrm{Mg}$ and $\mathrm{Cu}$ uptake in plants, especially in roots and in AMinoculated plants, while AM inoculation improved plant Fe, $\mathrm{Mg}$ and $\mathrm{Cu}$ uptake with exceptions for roots at $4000 \mathrm{mg} \mathrm{kg}^{-1} \mathrm{Mo}$ (Fig. 3e-j). Plant uptake mechanisms for molybdate and Fe are closely correlated..$^{45}$ Excess Mo in plants may interfere with Fe metabolism, leading to toxicity symptoms such as chlorosis and yellowing. ${ }^{5}$ Our present results confirm that excess Mo reduced Fe uptake by plants, thus inducing Fe deficiency. The element $\mathrm{Fe}$ is essential for the composition of chlorophylls and their functions in photosynthesis. The reduced Fe in shoots may explain the poorer growth and lower photosynthesis rate of the plants treated with Mo. Meanwhile, AMF help plants to acquire 


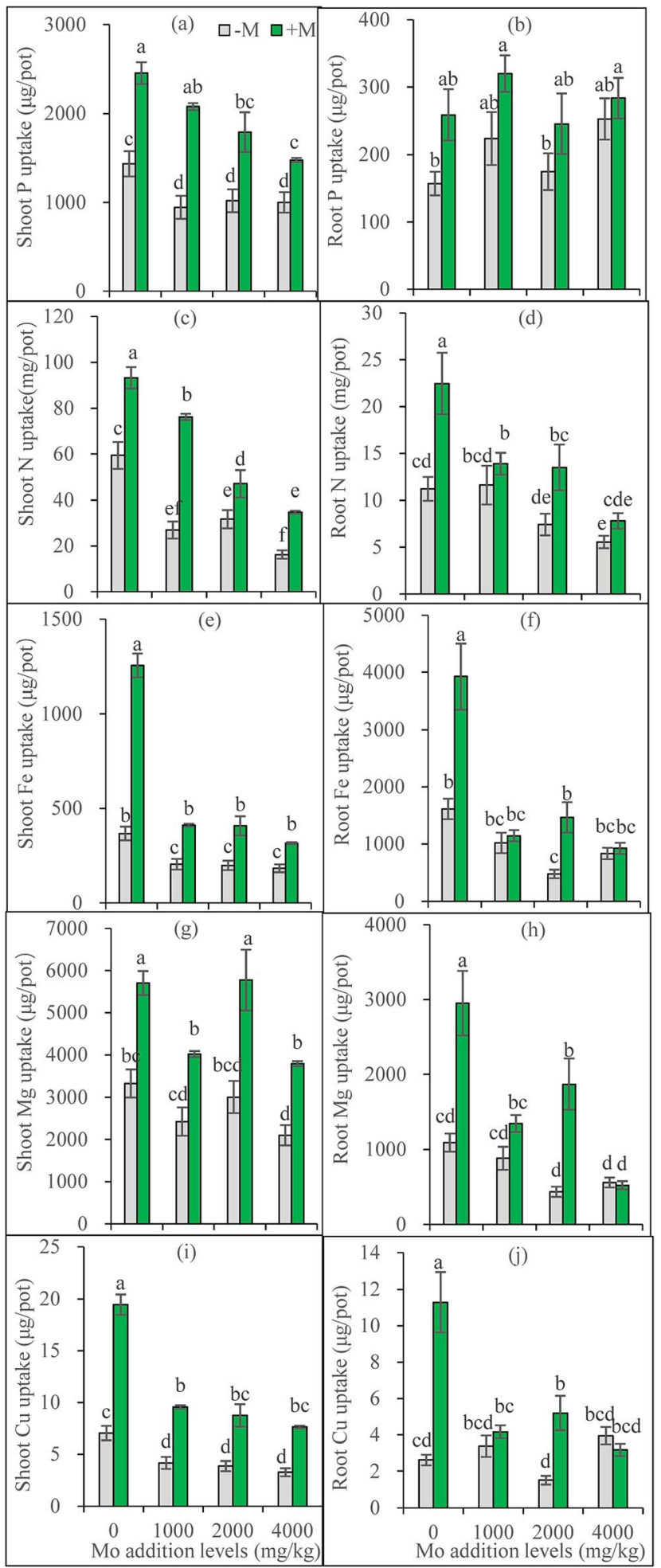

Fig. 3 Uptake of $\mathrm{P}, \mathrm{N}, \mathrm{Fe}, \mathrm{Mg}$ and $\mathrm{Cu}$ in maize shoots (a, $c, \mathrm{e}, \mathrm{g}$ and $\mathrm{i}$ ) and roots (b, $d, f, h$ and $j)$. $-M$ and $+M$ represent non $A M$-inoculation and inoculation with $C$. etunicatum BEG 168, respectively. Different letters on the bars indicate significant differences among all means in different treatments using a one-way ANOVA followed by the Duncan's multiple range test $(P<0.05)$. more Fe and thus alleviate the Mo-induced Fe deficiency, which represent one mechanism for AM plants to resist Mo toxicity.

$\mathrm{Mg}$ ion occupies the center of chlorophyll a molecules, and also acts as a cofactor of some key enzymes, thus taking part in numerous physiological and biochemical processes such as photosynthesis, synthesis of nucleic acids and proteins. ${ }^{46}$ Although little has been known on $\mathrm{Mo}-\mathrm{Mg}$ interaction, $\mathrm{Mg}$ uptake in maize plants was decreased by Mo addition, nevertheless, which was significantly corrected by AM inoculation (Fig. $3 \mathrm{~g}$ and $\mathrm{h}$ ). These results are in accordance with the previous finding that AM colonization increased $\mathrm{Mg}$ uptake of maize plants. ${ }^{\mathbf{4}}$

In addition to $\mathrm{Fe}, \mathrm{Cu}$ also shows antagonistic relationships with Mo in plant nutrition. ${ }^{5}$ The excess Mo in plants must lead to a decrease in $\mathrm{Cu}$ uptake, which was confirmed by the present results. In comparison to $\mathrm{Fe}$ uptake, Mo addition exerted similar inhibitory influence on $\mathrm{Cu}$ uptake in plants. In accordance with previous studies that AM associations help to absorb micronutrients including $\mathrm{Fe}$ and $\mathrm{Cu},{ }^{48}$ the present results show that AMF displayed promoting effects on $\mathrm{Cu}$ nutrition under Mo stress. More interestingly, plants containing $>5 \mathrm{mg} \mathrm{Mo} / \mathrm{kg}$ DWs may disturb the assimilation and metabolism of $\mathrm{Cu}$, and cause molybdenosis in animals feeding them. ${ }^{5}$ The AMF-increased $\mathrm{Cu}$ in plants used as fodder may be of significance for animal health.

\section{Two-way ANOVA analysis}

Two-way ANOVA results were summarized in Table 1. Different from the one-way ANOVA results, soil $\mathrm{pH}$ was not significantly influenced by Mo addition, AM inoculation, and their interaction. Both Mo addition and AM inoculation significantly

Table 1 Significance levels ( $F$ values) of Mo addition levels, AM inoculation, and their interactions on measured variables based on twoway ANOVA analysis ${ }^{a}$

\begin{tabular}{llll}
\hline Variables & Mo addition & AM inoculation & Mo $\times$ AM \\
\hline Soil pH & $2.86 \mathrm{~ns}$ & $0.01 \mathrm{~ns}$ & $3.33 \mathrm{~ns}$ \\
Shoot DWs & $16.66^{* *}$ & $115.35^{* *}$ & $2.81 \mathrm{~ns}$ \\
Root DWs & $7.03^{* *}$ & $25.69^{* *}$ & $3.25^{*}$ \\
Net photosynthesis & $3.83^{*}$ & $26.00^{* *}$ & $0.68 \mathrm{~ns}$ \\
Transpiration rate & $3.15^{*}$ & $6.48^{*}$ & $0.42 \mathrm{~ns}$ \\
Chl $a$ conc. & $23.85^{* *}$ & $14.67^{* *}$ & $10.51^{* *}$ \\
Chl $b$ conc. & $25.15^{* *}$ & $5.93^{*}$ & $5.49^{* *}$ \\
Chl $a+b$ conc. & $28.00^{* *}$ & $11.34^{* *}$ & $8.55^{* *}$ \\
Carotenoid conc. & $26.47^{* *}$ & $7.58^{*}$ & $9.27^{* *}$ \\
Shoot Mo conc. & $145.1^{* *}$ & $93.34^{* *}$ & $15.17^{* *}$ \\
Root Mo conc. & $49.84^{* *}$ & $56.84^{* *}$ & $6.18^{* *}$ \\
Shoot P uptake & $10.82^{* *}$ & $86.10^{* *}$ & $2.53 \mathrm{~ns}$ \\
Root P uptake & $2.31 \mathrm{~ns}$ & $10.44^{* *}$ & $0.49 \mathrm{~ns}$ \\
Shoot N uptake & $58.90^{* *}$ & $108.20^{* *}$ & $7.70^{* *}$ \\
Root N uptake & $10.91^{* *}$ & $17.96^{* *}$ & $2.74 \mathrm{~ns}$ \\
Shoot Fe uptake & $113.56^{* *}$ & $211.32^{* *}$ & $51.25^{* *}$ \\
Root Fe uptake & $25.85^{* *}$ & $24.72^{* *}$ & $8.68^{* *}$ \\
Shoot Mg uptake & $9.89^{* *}$ & $68.72^{* *}$ & $1.23 \mathrm{~ns}$ \\
Root Mg uptake & $16.29^{* *}$ & $37.72^{* *}$ & $8.24^{* *}$ \\
Shoot Cu uptake & $60.29^{* *}$ & $216.48^{* *}$ & $16.94^{* *}$ \\
Root Cu uptake & $10.09^{* *}$ & $33.28^{* *}$ & $15.04^{* *}$ \\
\hline
\end{tabular}

${ }^{a}$ Significance levels: ${ }^{*} P<0.05 ;{ }^{* *} P<0.01$. 
influenced plant shoot and root DWs, however, a significant interaction between them occurred on root DWs, but not on shoot DWs. The $F$ values suggest AM inoculation produced more significant impacts on plant growth than Mo addition, and both variables influenced more significantly on shoot DWs than on root DWs. Leaf photosynthesis and gas exchange were influenced significantly by Mo addition and AM inoculation separately, but not by their interactions. The concentrations of $\operatorname{chl} a, \operatorname{chl} b$, and carotenoid in leaves and Mo concentrations in shoots and roots were all significantly influenced by Mo addition, AM inoculation, and the interactions between them. By comparing the $F$ values, Mo addition showed more pronounced influences than AM inoculation (except root Mo concentration). Both Mo addition and AM inoculation significantly influenced plant uptake of $\mathrm{P}, \mathrm{N}, \mathrm{Fe}, \mathrm{Mg}$ and $\mathrm{Cu}$ (except Mo addition on root $\mathrm{P})$, and AM inoculation produced more significant influences than Mo addition based on the $F$ values (except for root $\mathrm{Fe}$ ). However, significant interactions were only observed on shoot $\mathrm{N}$, shoot $\mathrm{Fe}$, root $\mathrm{Fe}$, root $\mathrm{Mg}$, shoot $\mathrm{Cu}$ and root $\mathrm{Cu}$. Combining the complex interactions between Mo addition and AM inoculation on plant growth and Mo accumulation, AM plants may have a specific strategy to increase their survival on Mo polluted sites.

Furthermore, our findings have implications for use of AMF in ecological restoration and phytoremediation of Mo-polluted sites. First, AM inoculation enhanced plant tolerance to Mo stress and improved plant nutrition, which implies AMF may contribute to ecological restoration of Mo-polluted sites via facilitating plants to grow better. Second, AMF increased both plant biomass and Mo concentrations in plant tissues, leading to a high Mo accumulation in plants especially in the aboveground parts, which consequently enhances phytoextraction efficiency of Mo from polluted soil, and suggests a great potential of AMF in phytoremediation of Mo-polluted sites.

\section{Conclusion}

In conclusion, our results found that excess Mo caused phytotoxicity in maize, including plant growth reduction, higher Mo concentrations in shoots and roots, and less uptake of essential nutrients $\mathrm{P}, \mathrm{N}, \mathrm{Fe}, \mathrm{Mg}$ and $\mathrm{Cu}$, but showed no dose-dependent effects on Mo accumulation in plants. Inoculation with C. etunicatum BEG 168 further enhanced Mo concentrations in maize plants, but still showed positive plant growth-promoting effects, including mineral nutrient uptake, leaf pigment contents and photosynthetic properties. AMF could alleviate Mo availability and toxicity by decreasing Mo translocation from roots to shoots and mediating soil $\mathrm{pH}$. Our results indicate that AMF may play beneficial roles in ecological restoration and phytoremediation of Mo-polluted sites, but the potential health risk for animals induced by AMF-increased Mo content in plants should be considered.

\section{Conflicts of interest}

The authors declare that there are no conflicts of interest.

\section{Acknowledgements}

This work was supported by the Program for Science \& Technology Innovation Talents in Universities of Henan Province (18HASTIT013), the National Natural Science Foundation of China (31670499, 41471395), the Doctoral Foundation of QUST (0100229003), Key Laboratory of Mountain Surface Processes and Ecological Regulation, CAS (20160618), Laboratory for Earth Surface Processes, Ministry of Education (201612), the Innovation Team Foundation (2015TTD002) and Student Research Training Program (2015135) of Henan University of Science and Technology.

\section{References}

1 B. N. Kaiser, K. L. Gridley, J. N. Brady, T. Phillips and S. D. Tyerman, Ann. Bot., 2005, 96, 745-754.

2 W. S. Ferguson, A. H. Lewis and S. J. Watson, J. Agric. Sci., 1943, 33, 44-51.

3 R. E. Lucas, Cooperative Extension Service, Michigan State University, 1967.

4 U. C. Gupta, Molybdenum in Agriculture, Cambridge University Press, 1997.

5 D. C. Adriano, Trace Elements in Terrestrial Environments: Biogeochemistry, Bioavailability and Risks of Metals, Springer, New York, 2001.

6 C. Geng, Y. Gao, D. Li, X. Jian and Q. Hu, J. Geochem. Explor., 2014, 144, 273-281.

7 Z. L. Xiao, Q. Cong and J. Qu, Sci. Technol.: Eng., 2010, 10, 5831-5834.

8 J. Qu, X. Yuan, L. L. Wang and N. Wang, Environ. Prot. Sci., 2007, 33, 36-38.

9 T. Jia, Y. Y. Jia, S. J. Yu, Y. M. Qu, Z. L. Jiang, Y. H. Chen and G. Wang, Environ. Monit. China, 2015, 31, 45-49.

10 A. A. Akinsemolu, J. Cleaner Prod., 2018, 182, 139-155.

11 S. E. Smith and D. J. Read, Mycorrhizal Symbiosis, Academic Press, 3rd edn, 2008.

12 S. Meier, F. Borie, N. Bolan and P. Cornejo, Crit. Rev. Environ. Sci. Technol., 2012, 42, 741-775.

13 L. Cabral, A. J. Giachini and J. O. Siqueira, World J. Microbiol. Biotechnol., 2015, 31, 1655-1664.

14 F. Wang, Crit. Rev. Environ. Sci. Technol., 2017, 47, 19011957.

15 F. Y. Wang, Z. Y. Shi, X. F. Xu, X. G. Wang and Y. J. Li, Environ. Sci.: Processes Impacts, 2013, 15, 794-801.

16 F. Y. Wang, L. Wang, Z. Y. Shi, Y. J. Li and Z. M. Song, J. Plant Growth Regul., 2012, 31, 549-559.

17 G. A. Alloush, S. K. Zeto and R. B. Clark, J. Plant Nutr., 2000, 23, 1351-1369.

18 P. S. Raju, R. B. Clark, J. R. Ellis and J. W. Maranville, J. Plant Nutr., 1987, 10, 1331-1339.

19 Z. Shi, F. Wang, C. Zhang and Z. Yang, J. Plant Nutr., 2011, 34, 1096-1106.

20 F. Wang, X. Liu, Z. Shi, R. Tong, C. A. Adams and X. Shi, Chemosphere, 2016, 147, 88-97.

21 H. Vierheilig, A. P. Coughlan, U. Wyss and Y. Piché, Appl. Environ. Microbiol., 1998, 64, 5004-5007. 
22 D. I. Arnon, Plant Physiol., 1949, 24, 1-15.

23 F. Y. Wang, X. G. Lin and R. Yin, Pedobiologia, 2007, 51, 99109.

24 M. González-Guerrero, K. Benabdellah, N. Ferrol and C. Azcón-Aguilar, Mechanisms underlying heavy metal tolerance in arbuscular mycorrhizas, in MycorrhizasFunctional Processes and Ecological Impact, ed. C. AzcónAguilar, J. M. Barea, S. Gianinazzi and V. GianinazziPearson, Springer, 2009, pp. 107-122.

25 W. Zimmer and R. Mendel, Plant Biol., 1999, 1, 160-168.

26 R. J. Campo, R. S. Araujo and M. Hungria, Field Crop. Res., 2009, 110, 219-224.

27 B. Kovács, A. Puskás-Preszner, L. Huzsvai, L. Lévai and É. Bódi, Plant Physiol. Biochem., 2015, 96, 38-44.

28 S. Xu, C. Hu, Q. Tan, S. Qin and X. Sun, Plant Physiol. Biochem., 2017, 123, 75-80.

29 S. P. Mcgrath, C. Micó, F. J. Zhao, F. J. Zhao, J. L. Stroud, H. Zhang and S. Fozard, Environ. Pollut., 2010, 158, 30853094.

30 R. Kluge, Molybdenum toxicity in plants, in Proceedings Mengen-und Spurenelemente Arbeitstagung, ed. M. Anke, B. Groppel, H. Gürtler, M. Grün, I. Lombeck and H. J. Schneider, Institut für Pflanzenernährung, Leipzig, 1983, pp. 10-17.

31 M. Miransari, Plant Biol., 2010, 12, 563-569.

32 H. Zhang, N. Xu, X. Li, J. Long, X. Sui, Y. Wu, J. Li, J. Wang, H. Zhong and G. Y. Sun, Front. Plant Sci., 2018, 9, 1156.
33 S. Wang, F. Wang and S. Gao, Environ. Sci. Pollut. Res., 2015, 22, 2837-2845.

34 T. Zhang, Y. Hu, K. Zhang, C. Tian and J. Guo, Ind. Crops Prod., 2018, 117, 13-19.

35 S. Kannan and S. Ramani, Plant Physiol., 1978, 62, 179-181. 36 S. Khandelwas, Indian Fern J., 1988, 5, 104-109.

37 A. J. M. Baker, J. Plant Nutr., 1981, 3, 643-654.

38 W. Sun and H. M. Selim, Geoderma, 2017, 308, 60-68.

39 H. Liu, C. Hu, X. Hu, Z. Nie, X. Sun, Q. Tan and H. Hu, J. Plant Nutr., 2010, 33, 1751-1760.

40 H. Heuwinkel, E. A. Kirkby, J. Lebot and H. Marschner, J. Plant Nutr., 1992, 15, 549-568.

41 V. Karandashov and M. Bucher, Trends Plant Sci., 2005, 10, 22-29.

42 M. Yu, C. Hu, X. Sun and Y.-h. Wang, J. Integr. Agric., 2010, 9, 355-361.

43 A. López-Pedrosa, M. González-Guerrero, A. Valderas, C. Azcón-Aguilar and N. Ferrol, Fungal Genet. Biol., 2006, 43, 102-110.

44 J. Pérez-Tienda, P. S. Testillano, R. Balestrini, V. Fiorilli, C. Azcón-Aguilar and N. Ferrol, Fungal Genet. Biol., 2011, 48, 1044-1055.

45 B. Florian, Front. Plant Sci., 2014, 5, 28.

46 Z. C. Chen, W. T. Peng, J. Li and H. Liao, Semin. Cell Dev. Biol., 2018, 74, 142-152.

47 H. Zaremaivan, N. Khanpourardestani and F. Ghanati, J. Plant Nutr., 2017, 40, 2026-2032.

48 H. Marschner and B. Dell, Plant Soil, 1994, 159, 89-102. 